\title{
Adherence to fibromyalgia treatment: challenges and impact on the quality of life
}

\author{
Adesão ao tratamento da fibromialgia: desafios e impactos na qualidade de vida \\ José Oswaldo de Oliveira Júnior ${ }^{1}$, Júlia Villegas Campos Ramos²
}

DOI 10.5935/2595-0118.20190015

\section{ABSTRACT}

BACKGROUND AND OBJECTIVES: Fibromyalgia is a chronic and idiopathic syndrome, characterized by a general distributed pain, more prevalent in women. Its pathophysiology remains unclear. Its chronicity implies an exclusively symptomatic treatment, often unsatisfactory. The lack of adherence to the established treatment is quite common. The objective of this study is to present a review of the adherence to the fibromyalgia syndrome treatment.

CONTENTS: The concept of adherence to the fibromyalgia syndrome treatment, its classification, the identification of its measurement options, and the detection of its causes are detailed, revised and updated.

CONCLUSION: The review of the literature regarding the adherence to the fibromyalgia syndrome treatment points to a large number of nonconformity of prescription, in general with the prevalence of the adoption of the reduction of the recommended dose and the interruption of the treatment, over possible overdoses and self-medication. The study of the causes that led to the non-adherence to the treatment elects the characteristics of the syndrome as the great villain for its occurrence. However, other associated factors such as the age of the subject with fibromyalgia, the intensity of the pain, the established polypharmacy, the quality of the doctor-patient relationship and the socioeconomic variables were also listed. The patient's quality of life was always higher in patients with higher adherence to treatment and persistence. Patients' quality of life indices may indicate the level of commitment to treatment adherence, and vice versa.

Keywords: Adherence, Compliance, Fibromyalgia, Nonpharmacologic treatment, Persistence, Pharmacologic treatment, Therapeutic conformity.

José Oswaldo de Oliveira Júnior - Dhttps://orcid.org/0000-0003-1748-4315; Julia Villegas Campos Ramos - Dhttps://orcid.org/0000-0003-4674-2459.

1. Hospital A C Camargo, Săo Paulo, SP, Brasil.

2. Hospital do Servidor Público Estadual de São Paulo, São Paulo, SP, Brasil.

Submitted in October 23, 2018

Accepted for publication in January 18, 2019

Conflict of interests: none - Sponsoring sources: none

Correspondence to:

José Oswaldo de Oliveira Júnior

E-mail: jo.oliveirajr@yahoo.com.br

(C) Sociedade Brasileira para o Estudo da Dor

\section{RESUMO}

JUSTIFICATIVA E OBJETIVOS: A fibromialgia é uma síndrome crônica e idiopática, caracterizada por queixa dolorosa de distribuição generalizada, mais prevalente em mulheres. A sua fisiopatologia continua náo totalmente esclarecida. Sua cronicidade implica em tratamento exclusivamente sintomático e muitas vezes insatisfatório. A falta de adesão ao tratamento instituído é bastante comum. O objetivo deste estudo foi apresentar uma revisão sobre a adesão do tratamento da síndrome fibromiálgica. CONTEÚDO: O conceito de adesão ao tratamento da síndrome fibromiálgica, sua classificação, a identificação das opçóes de sua mensuração, e a detecção de suas causas são detalhados, revisados e atualizados.

CONCLUSÃO: A revisão da literatura referente à adesão ao tratamento da síndrome fibromiálgica mostra um grande contingente de inconformidade de prescrição, em geral predominando a adoção da redução da dose orientada e a interrupção do próprio tratamento, sobre possíveis sobredoses e automedicaçôes. O estudo das causas que levaram à falta de adesão ao tratamento elege as características da própria síndrome como a grande vilã para sua ocorrência; embora, tenham sido também elencados outros fatores associados como a idade do portador da síndrome fibromiálgica, a intensidade da dor, a polifarmácia instituída, a qualidade da relação médico-paciente, e as variáveis socioeconômicas. A qualidade de vida dos pacientes sempre foi maior naqueles cuja adesão e persistência ao tratamento foram maiores. Os índices de qualidade vida dos pacientes podem indicar o nível de comprometimento com a adesão ao tratamento, e vice-versa.

Descritores: Adesão, Conformidade, Conformidade terapêutica, Fibromialgia, Persistência, Tratamento farmacológico, Tratamento não farmacológico.

\section{INTRODUCTION}

Fibromyalgia (FM) is a chronic pain syndrome with complex, multifactorial, and yet not fully understood etiopathogenesis. The most striking FM feature is generalized musculoskeletal pain, associated with a sleep disorder, fatigue, cognitive alterations, and psychic disorders.

FM prevalence ranges from 0.2 to $6.6 \%$ in the general population, with women more affected than men, in a ratio of $9: 1$, being more frequent in the age group between 40 and 55 years. The prevalence of psychic disorders, especially depression, among FM patients ranges from 49 to $80 \%{ }^{1}$. 
Treatment adherence of fibromyalgia syndrome (FMS) can be defined as the extent to which the patient's behavior is in line with the recommendations of the health care professional (or group of professionals) ${ }^{2}$ regarding drug use, a proper diet up or changes in lifestyle. Such recommendations aim at the remission or control of the syndrome, and the consensual obedience can make the difference between success or failure.

\section{THE CONCEPT OF ADHERENCE AND ITS EVOLUTION}

Research and discussion on adherence have evolved from a one-dimensional approach limited to the follow-up of a pharmacological regimen, to the understanding of the factors involved in the treatment success or failure. The focus has been extended beyond the patient. Nowadays, it is widely recognized that several factors mediate the treatment of a disease or health condition.

The adherence model proposed by the World Health Organization (WHO) illustrates the participation of some factors in the adherence process, namely aspects related to the health care team, factors related to the treatment itself, aspects related to the disease, the patient and socioeconomic factors ${ }^{2}$.

\section{Fibromyalgia characteristics and the importance symp- toms refractiveness}

Aspects related to fibromyalgia are particularly crucial factors in adherence to its treatment.

The acceptance of the diagnosis of a non-curable disease is far from tacit and is often associated with the denial of both the disease and its treatment. Even in the medical field, there are still questions about considering FM as an isolated entity. The poor findings in the physical examination of these patients are remarkable, being restricted to the presence of diffuse points of pain and often with itinerant preferential commitment.

One of the main reasons that lead a patient not to adopt or interrupt a prescription, whether pharmacological, dietary, behavioral or the combination of one or more previous recommendations, is the persistence of symptoms, especially painful ones.

The remarkable FM prevalence in $2 \%$ of the world population, associated with the suffering attributed to it, to its pathophysiology not yet completely revealed, to the prognosis regarding the possibility of cure, and to the unsatisfactory results in the control of its symptoms ${ }^{3}$, especially the painful ones, make it a huge challenge when it comes to treatment adherence.

\footnotetext{
Adherence to pharmacological treatment in fibromyalgia Inadequate adherence and persistence in pharmacological treatment are old problems. When the patient fails faithful obedience and adherence to the prescribed dosage, changes may occur, consequently changing the relationship between probable benefits and respective risks. In FM, there is a large gap to be shared with the patient about his/her diagnosis, illness, possible risks, and benefits on whether or not to adhere to a proposed treatment. Patient has in mind that whatever is
}

the treatment, pharmacological or not, he will not be cured; and moreover, although making him suffer, it will not kill him: "He will die with it, not because of it". In this scenario, the possible benefits and risks inherent to adherence seem to lose relevance from the point of view of the treatment target. It is important to invest in the education of the medical care team to clarify each prescribed item. An example is an orientation not to use a particular drug which, although providing identifiable analgesia, may pose a risk to the integrity of vital organs.

Several studies agree that partial or total failure of adherence to pharmacological prescription regimes results in increased morbidity and mortality due to a wide variety of diseases, as well as increased costs involved with the respective medical care ${ }^{4-8}$.

\section{Measuring the adherence to the fibromyalgia treatment by patients}

A number of non-compliance modalities have been compiled, among them, the lack of pharmacological compliance (also known as lack of adherence to pharmacotherapy), which corresponds to the disobedience to the recommendations made by the prescriber regarding time, dose and/or frequency of one or a set of drugs. Thus, on the other hand, pharmacological adherence can be defined as "the extent to which a patient respects the use (by the expressly oriented route) of the drug (without substitutions, even if by similarity), at the recommended dose and in the respective time interval prescribed". Adherence, or compliance, can be measured over a period and reported as a percentage. The definition is operationalized in prospective dose assessments and relates them to what was originally prescribed. The standardization of compliance is prepared for a patient whose prescription conceives the once-daily administration of the drug.

Electronic monitoring provides sufficient detail to calculate the number of doses taken daily, as well as whether doses have been taken at appropriate intervals (e.g., approximately 12 hours for a dose twice a day). Additional details can be obtained, such as the number of days with extra doses or the number of days in which none of them were administered ${ }^{9}$.

\section{Persistence in adherence}

Another non-compliance modality is the abandonment of a particular treatment before the end of the prescribed period. So, the persistence of pharmacological adherence can be defined as "the time duration from the beginning of the therapy to its discontinuation".

The continuity in taking any amount of drug is consistent with the definition of persistence. This definition can be operationalized in prospective and retrospective assessments, determining the beginning of the treatment (or a point in time during a chronic treatment), and another point in the timeline defined as the end of the observation period.

Patients with FM can receive drugs whose stable analgesic effects are expected only after a relatively long period of administration. The therapeutic outcome obtained by these drugs should consider the persistence of treatment adherence. 
Often, patients need clarification about the drug and are unaware of the elapsed time between start taking the drug and the analgesic effect. After a short period without the desired relief, they end up quitting the treatment. The history data provided by those patients in future medical visits erroneously reports such drugs as ineffective, not being considered for further testing ${ }^{9,10}$.

Persistence, by definition, is reported as a continuous variable in terms of the number of days for which the therapy was available. Persistence can also be reported as a dichotomous variable measured at the end of a predefined period (e.g., 12 months), considering patients as "persistent" or "non-persistent".

\section{Definitions and standardizations for persistence assess- ment and treatment adherence}

Clinical results of treatment are affected not only by how patients take their drugs but also by the period they are taken. Thus, adherence from one side and persistence from another should be defined and measured separately to characterize the behavior of comprehensively taking a prescribed drug.

The adherence and persistence approaches provide a richer understanding of behavior versus drug treatment. The adoption of the proposed definitions focuses on the promotion of consistent terminology and methodology that may assist the conduct, analysis, and interpretation of scientific data collected in studies on pharmacological adherence ${ }^{11}$.

Definitions focus on future standardization in surveys to allow comparisons between reports and use of adherence and persistence data for drug-economic analyzes. Standardization may contribute to future health policy decisions based on consistent evidence.

The definition is operationalized in retrospective assessments such as the number of doses dispensed in relation to the dispensing period. Conformity with prescription is assumed when the drug is dispensed ${ }^{11}$.

\section{Advantages of supervised home-administration regimens}

Compliance with drug regimens and follow-up visits of psychiatric patients was evaluated, and the criteria for good adherence were met ${ }^{12}$ in less than one-third of them. Adherence was significantly related to the positive belief about the drug usefulness, treatment duration shorter than five years, pharmacological dosage once or twice a day and drug supervision at home. When those with low adherence received the same dosage regimen, home supervision and when they received convincing counseling about the drug usefulness and possible efficacy, there was an improvement in adherence and a consequent reduction in the rate of relapse, significantly lower than in the controlled group at the end of one-year follow-up. The importance of family support and understanding the patients' cultural histories to ensure compliance were highlighted ${ }^{12}$.

\section{The probable prognosis of the treated disease or syndrome and adherence}

Even in diseases with potentially deadly outcomes such as cancer, there is a significant non-compliance rate of the pre- scription, especially when the patient administers the drug ${ }^{13}$. Treatment duration, with no fixed time as in the case of FM, seems to have significant influence for the discontinuation or lack of adherence.

The non-compliance transcends the limit of the categories of diseases and age group. However, this is more prevalent during adolescence, when the transition process from parents' dependence to autonomy produces confusion over who is responsible for administering the drug.

Non-compliance may result in misjudgment of the efficacy of a drug or regimen that may require additional testing, dose modification, treatment course, and hospitalization.

Currently, in oncology referral centers, such as the AC Camargo Cancer Center and the MD Anderson Cancer Center, a large percentage of pediatric cancer patients are treated according to research protocols. In these scenarios, non-conformity may result in erroneous or inconsistent discoveries, potentially affecting the survey results and consequently its conclusions ${ }^{13}$.

With the availability of venous accesses and sophisticated but easy-to-operate pumps, it is increasingly possible to administer parenteral drugs at home. This adds a new dimension to self-administration that previously involved primarily oral therapy.

Several factors relating to patient, disease, health providers and treatment characteristics determine how well a given regimen is followed. As it involves a significant number of determinants, it is not often possible to identify non-compliant patients or to predict the patient's level of adherence to treatment with any degree of certainty. The main factors in any successful therapy include the availability of effective drugs and adherence to the therapeutic regimen ${ }^{13}$.

With the advent of more successful treatments for cancer in childhood and adolescence, the compliance factor is becoming more important because today, therapy has a curative rather than palliative intent. However, this does not apply to FM, where therapies remain exclusively symptomatic. The availability of questionnaires, tests, and devices can help, to some degree, to examine the patient's degree of adherence ${ }^{13}$.

Characteristics of the treated disease or syndrome and adherence

Family and social support, individualized programs, reminders to reduce forgetfulness, personalized needs assessment and education can reduce non-compliance. Compliance is a complex and multifaceted issue that is still poorly understood and requires additional research ${ }^{13}$.

Regarding the aspects related to the disease, it is possible to highlight the symptoms magnitude, the disease characteristics and its evolution, chronicity and the impact on the patient's life. Regarding chronic pain, a recent literature review showed that the rate of non-adherence to prescriptions for chronic pain ranged from 8 to $62 \%$. It is in this universe that FMS falls ${ }^{14,15}$. Underuse was more frequent than overuse and was associated with active coping strategies and self-medication in most studies. Age, pain intensity, dosage, polypharmacy, quality 
of the physician-patient relationship, the class of drugs prescribed and the perception of the need for a continuous analgesic drug were factors associated with non-adherence ${ }^{14}$.

Socioeconomic variables also interfere with adherence. Among the several factors, we can list the cost of the drug, health policies, access to health service, waiting time versus service time, gender, educational level, and social class.

Factors associated to the patient include lifestyle, social network, family context, age group, emotional state, associated diseases, cognitive aspects (e.g., dysfunctional beliefs and disbeliefs) to previous experience with the disease. Regarding beliefs, many patients resist the use of opioids, antidepressants, and anticonvulsants by the associated myths or stigmas.

The aspects related to the healthcare team are the team-patient relationship, communication, professionals' beliefs, among others. This myriad of elements clearly indicates the complexity of the adherence process.

Regarding treatment, its positive or undesirable effects, access to treatment, and complex therapeutic schemes are important factors to be highlighted.

The communication skills of the physician and the healthcare team are essential in this context. The operation and effects of the drug or procedure should be clearly explained and the prescriptions clear and legible.

Despite the importance of the theme, and although theoretical discussions have been taking place since the 1950s, the subject is little investigated ${ }^{16}$ and it is even less investigated when it comes specifically to FM, whose consensus and unified terminological adoption occurred only in the late 1980s.

Chronic pain is a public health problem and is classified as a difficult-to-control pain, characterized by frequent treatment failure. In the clinical context of the patients with FMS it is possible to more easily perceive some elements, among them the reduced effect of the drug, in many cases not occurring the complete remission of the symptoms, the adverse effects (e.g. drowsiness, loss of libido, numbness, constipation), and its high $\operatorname{cost}^{17}$.

\section{Impact on the quality of life of patients with fibromyalgia}

Patients with FM have a tremendous negative impact on their quality of life (QoL), they feel a high degree of disability, even in daily tasks. This increase or predisposes to symptoms of depression and anxiety, which in turn worsens pain and closes the chronicity cycle. This impact on QoL is directly related to the general economic cost of the disease.

Compared to other chronic diseases, FM has been shown as a condition that mostly demands health care. The high costs generated by this condition are indirect. They involve loss of productivity, decrease in the number of hours and days worked, unemployment and early withdrawal from the labor market. Direct and indirect costs increase according to the severity of the disease ${ }^{17}$.

\section{Adherence and persistence to the pharmacological treatment of fibromyalgia.}

FM treatment includes non-pharmacological and pharmacological approach. The non-pharmacological approach consists of a physical activity program and, in those patients with mood disorder, or without coping strategies, the cognitive-behavioral therapy ${ }^{13}$.

Pharmacological treatment includes pain moderators such as selective serotonin reuptake inhibitor antidepressants (alone) and so-called dual (serotonin and noradrenaline), non-selective tricyclic agents (such as amitriptyline and cyclobenzaprine) and anticonvulsant agents (such as pregabalin and

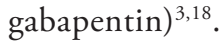

Adherence to FM pharmacological treatment is considered low worldwide, and varies among the different drugs, with tricyclic agents being the most rapidly abandoned, and adherence was higher in the group that received more selective antidepressants ${ }^{18-20,22}$. Among the more selective, noradrenaline and serotonin reuptake inhibitors, also known as dual inhibitors, similar to tricyclics, produce central analgesia acting on descending inhibitory nerve pathways. In general, duals have a better tolerability and adverse effects profile than tricyclics, which may explain their adherence and persistence rates ${ }^{3}$.

The discontinuity rate in the general use of the standard tricyclic, amitriptyline (AMT), is around 35\%, and the greatest motivator for discontinuity is its adverse effects. However, these studies included high doses of AMT, as in the case of treatment for depression. Also, in the case of very low doses, the unit dose method may overestimate the low adherence ${ }^{19}$. Another motivator for discontinuation or non-initiation of AMT use and other tricyclics for analgesic purposes is the absence of official label documentation for this particular indication. The exclusive label of antidepressant may induce the potential reader to interpret that the prescriber may consider the pain, therapeutic targets, as of primary or predominantly psychoactive origin. Despite scientific evidence of the tricyclics' analgesic effect, in many countries, the leaflet remains obsolete, unchanged, due to costs of a review and update, incompatible with the low unit marketing price of these drugs.

The FDA approved only three drugs for the FM treatment. One is pregabalin, and the other two are dual antidepressants: duloxetine and milnacipran. Duloxetine has the best efficacy evidence for FM treatment, usually in a single daily dose of $60 \mathrm{mg}$ (ranging from 30 to $120 \mathrm{mg}$ ), mainly when there is depressive morbidity associated, with or without anxiety. In addition to anxiety, depression is also another morbidity that can prevent the patient to adhere to treatment. Di Matteo et al. ${ }^{4}$ concluded that the risk of non-adherence is $27 \%$ higher in this group, regardless the underlying disease to be treated.

Cui et al. ${ }^{20}$ evaluated the adherence of patients with fibromyalgia to the treatment with duloxetine and showed that one-third of them had a strong adherence, and among them, the predictive factors for better adherence were age above 35 years and previous use of selective antidepressants (serotonergic inhibitors or serotonergic and noradrenergic). The same group of investigators, in a study involving more than 18,000 patients, concluded that adherence and persistent use of duloxetine were similar in groups of patients with depressive disorder, FM and osteoarthritis, and significantly higher than the results found for patients with chronic lower back pain ${ }^{21}$. 
A group of anticonvulsants called gabapentinoids are useful as analgesics in several situations. They act on the alpha2-delta subunits of receptors that control ionic channels of dynamic permeability to voltage-dependent calcium. Inhibitory action in these subunits reduces the release of excitatory neurotransmitters in painful pathways, resulting in analgesia. The approval provided by the official US Food and Drug Administration (FDA) for these drugs in the FM treatment allowed the inclusion of that indication in the leaflet and the lay advertisement.

Sanchez et al. ${ }^{22}$ recorded data on the adherence and persistence of patients with FM, post-herpetic painful neuropathy and diabetic peripheral polyneuropathy treated with gabapentinoid known as pregabalin.

Sanchez et al. ${ }^{22}$ showed that the majority of patients prescribed with pregabalin received lower doses than those considered ideal for the best response $(450 \mathrm{mg})$. Costs with the pharmacy were lower due to the use of lower doses. However, both the therapeutic result and adherence were significantly lower in the same group. The total medical costs among the group using recommended doses and those using lower doses were comparable, suggesting that the prescription of the recommended therapeutic dose can increase adherence without increasing the costs involved.

\section{Adherence to the treatment of fibromyalgia and the physi- cian-patient relationship}

Dobkin, Sita and Sewitch ${ }^{23}$ evaluated 142 patients with FM recruited from tertiary and community centers. They measured adherence, pain, psychological changes, coping, the perception of social support, and the number of associated diseases.

They also compared the physician's and the patient's interpretation regarding the state of health of the FM-carrier. The results showed that the greater adherence to treatment is related to the lower psychological changes degree and the lower physician/patient disagreement regarding the patient's health state ${ }^{23}$.

Data on health status differed between therapist and patient perspectives. The physician generally attributed less attention to the patient's emotional well-being in relation to the note he/ she attributed to himself/herself in his/her own assessment. Such discrepancy may lead to a lack of confidence by the patient, believing that the physician attributed his/her symptoms not to an organic cause but to an "emotional problem"23.

Regarding the presence of psychological changes such as depression and anxiety, the study is in agreement with others that also showed the negative association of these factors with the adherence.

Lack of hope and self-motivation, present in these cases, may impair the patient's commitment to any change, including treatment $t^{23}$.

\section{Patient's faithfulness or achievement and his/her adherence to treatment}

The challenge of "win the patient" for his/her own disease's treatment, in the case of FM, begins with the diagnosis.

Fibromyalgia, or fibromyalgia syndrome, is a diagnosis of exclusion, and it is only given after thorough medical history and physical examination, and a series of unchanged complementary tests.
It is not uncommon for the fibromyalgia patient to feel frustrated by not finding the expected explanation for his/her symptoms. In an attempt to reduce such frustration, Hyland et al. ${ }^{24}$ studied an original narrative to explain to the patient the FM's dysfunctional pain.

Hyland et al. ${ }^{24}$ studied the physician-patient relationship in the chronic pain research context of Kenny ${ }^{25}$, which stated that potentially curative interactions between physicians and their patients, which are not based on the biogenic model of the visible body or the psychogenic model of invisible pain, are needed to aid communication between patients with chronic pain and their physicians.

The narrative proposes that the patient's body is comparable to a computer, with FM being a predominant problem of programming (or "software") rather than structure (or "hardware"). This narrative invites the patient with FM to engage in non-pharmacological measures that may contribute to reprogram the "computer". The strategy also favors the patient by communicating that he/she can be the protagonist in a struggle that he/she will continue to face despite the difficulties.

The authors evaluated the patients' opinions regarding the proposed narrative and found great acceptance with a welcome perception ${ }^{25-27}$.

Several studies on adherence to treatment agree on the importance of the physician-patient relationship. The multidisciplinary team should clearly and patiently explain the diagnosis, the limitations of the medicine regarding the FM etiopathogenesis and the treatment of other chronic diseases.

The flexibility of access to the physician for clarification of questions that may arise regarding the dosage or adverse effects of the prescribed drug is a safety factor that may increase adherence to the treatment.

The proportion of patients who show significant improvement (reduction of at least $50 \%$ in pain) with currently available pharmacological treatment is low, generally 10 to $25 \%$ higher than placebo, and it is necessary to treat 4 to 10 patients to obtain the mentioned improvement. Therefore, dose optimization and the emphasis on the association of non-pharmacological therapy may motivate persistence when obtaining better results.

\section{Quality of life of patients with fibromyalgia}

QoL indicates the level of the basic and supplementary conditions of the human being. These conditions involve physical, mental, psychological and emotional well-being, social relationships such as family and friends, as well as health, education and other parameters affecting human life. The economist Galbraith created the concept in 1958, which conveys a different view of the priorities and effects of quantitative economic objectives.

According to Galbraith, political-economic and social goals should not be marked in terms of quantitative economic growth and material growth in living standards, but rather in qualitative improvement of human living conditions, which would be possible only through a better development of social infrastructure and the elimination of disparities, both regional and social, and to the defense and preservation of the environment. 
Obtaining a good QoL depends on the adoption of healthy habits, body care, balanced nutrition, healthy relationships, time for leisure and several other habits that make the individual feel good. As a consequence, the individual can use humor to deal with stressful situations, giving the sense of control over his/her own life.

QoL is different from the standard of living, although there is confusion between these two terms. Standard of living is a measure that quantifies the quality and quantity of goods and services that a particular person or group may have access to. FM, as already described, is a condition that is not yet fully understood, persistent, without cure, with an exclusively symptomatic treatment ${ }^{28,29}$ and that certainly does not promote a good level of QoL.

Pharmacological and non-pharmacological measures to minimize pain, relieve depression and improve sleep, provide limited success and are associated with adverse effects ${ }^{30}$. Even alternative forms of treatment do not bring great relief ${ }^{31}$. Many people have never experienced complete relief from their symptoms, even ephemerally ${ }^{31}$. Thus, what remains for those who suffer from FM is limited to managing the syndrome, i.e., learning to live and dealing with a wide variety of symptoms including diffuse pain, fatigue, non-restorative sleep, depression, anxiety, irritable bowel syndrome, multiple chemical sensitivity syndrome, premenstrual syndrome, stiffness, cognitive impairment, and restless legs syndrome.

Several studies have examined the QoL of patients with FM and found that their QoL is extremely low compared to other groups $^{32-37}$. In Brazil, a sample of women with FM was studied and revealed a lower pain threshold and worse QoL than a control group of healthy women, although no correlation was found between pain measurements and $\mathrm{QoL}^{38}$. Not only the lack of adherence to pharmacological treatment schemes occurs and implies a worse FM control, but physical activity programs are also affected by the lack of commitment in its execution and assiduity.

People with FM seem to have smaller social support networks than patients with other chronic diseases ${ }^{39,40}$, which probably contribute to lower QoL rates.

The ability to work also has an impact on QoL. People with FM lose it due to their symptoms. Such patients report a considerable negative impact on their QoL, and their level of perceived disability also seems to be influenced by their mental health condition. The psychological distress is greater compared with patients with other pain conditions ${ }^{41}$.

A significant number of fibromyalgia patients may use alcohol or other drugs in an attempt to obtain a bearable distance from reality, while others, unfortunately, choose suicide. The risk of these outcomes can be predicted and at least reduced with the evaluation and multiprofessional follow-up during patients' monitoring ${ }^{41}$.

\section{Fibromyalgia patients' needs under their own perspectives}

The satisfaction or non-satisfaction of patients in relation to their healthcare providers can have an impact on their attitudes and on how they deal with the disease, and thus have a nega- tive impact on QoL and the ability to manage their symptoms effectively ${ }^{18,42}$.

When asked what they expected from their professional caregivers (physicians, nurses, physiotherapists, psychologists, technicians, and attendants), more than half expected their support and access to further and better information about their illness. Nearly a third of FM patients simply wanted to know if they actually believed that the disease with which they were diagnosed really existed. These desires took precedence over the development of more effective drugs, more funding for research and better diagnosis ${ }^{18,24,43}$.

Patients are more satisfied when their physicians adopt a therapeutic set, not limited to the prescribed drugs, and use a greater variety of methods to deal with FM symptoms, showing more concern with them. The use of positive coping strategies can be therapeutic and reduce the severity of symptoms. Exercises and stress management techniques such as relaxation exercises, meditation, prayer, hobby, and conversation with friends, family, or healthcare professionals are forms of therapy for $\mathrm{FM}^{18,24,44}$.

The detection of the possibility of the domino effect or even a "vicious circle" that QoL problems can produce, and their clear communication, have a positive impact. For example, these effects are felt in the restrictions of daily activities caused by FM symptoms, which in turn can lead to a state of depression, and depression can progressively limit their activities, producing an even more pronounced depression ${ }^{24,45}$.

The lack of support and trust between FMS patients and their healthcare providers only increases the stress. When comparing other chronic pain conditions, the population suffering from FM is the one that receives less professional and social support. Support groups, whether traditional or using modern electronic means, can help ${ }^{46}$.

Fibromyalgia patients plead and need to be empowered to manage their symptoms. Such empowerment involves providing support, teaching on how to deal with strategies, and also opportunities to explore nontraditional therapies to manage their syndrome ${ }^{47}$.

\section{CONCLUSION}

The current review of the literature regarding adherence to FMS treatment shows a large contingency of prescription non-conformity, with the predominance of target dose reduction and discontinuation of treatment when compared to the rare cases of overdoses and self-medication.

The study of the causes leading to the lack of adherence and persistence to the treatment selects the characteristics of the syndrome itself as the great villain for its occurrence; although other associated factors such as the age, pain intensity, the polypharmacy instituted, the quality of the physician-patient relationship and the socioeconomic variables were also listed.

The QoL of the patient was always higher in those whose adherence and persistence to the treatment was higher. Patients' QoL indexes may indicate the level of commitment to adhere to treatment, and vice versa. 


\section{REFERENCES}

1. Lorente GD, Stefani LF, Martins MR. Cinesiofobia, adesão ao tratamento, dor e qualidade de vida em indivíduos com síndrome fibromiálgica. Rev Dor. 2014;15(2):121-5.

2. Sabaté E. Adherence to long-term therapies: evidence for action. World Health Organization. 2003.

3. Oliveira Jr JO, Almeida MB. The current treatment of fibromyalgia. Br J Pain. 2018;1(3):255-62.

4. DiMatteo MR, Giordani PJ, Lepper HS, Croghan TW. Patient adherence and medical treatment outcomes: a meta-analysis. Med Care. 2002;40(9):794-811.

5. Cramer JA. Partial medication compliance: the enigma in poor medical outcomes. Am J Manag Care. 1995;1(1):45-52.

6. Zyczynski TM, Coyne KS. Hypertension and current issues in compliance and patient outcomes. Curr Hypertens Rep. 2000;2(6):510-4.

7. Avorn J, Monette J, Lacour A, Bohn RL, Monane M, Mogun H, et al. Persistence of use of lipid-lowering medications: cross-national study. JAMA. 1998;279(18):1458-62.

8. Howell N, Trotter R, Mottram DR, Rowe PH. Compliance with statins in primary care. Pharm J 2004;272:1-40.

9. Burrell A, Wong P, Ollendorf D, Cramer JA. Defining compliance/adherence and persistence: ISPOR Special Interest Working Group. Value Health. 2005;8(6):A194-5.

10. Peterson AM, Nau DP, Cramer JA, Benner J, Gwadry-Sridhar F, Nichol M. A checklist for medication compliance and persistence studies using retrospective databases. Value Health. 2007;10(1):3-12.

11. Cramer JA, Roy A, Burrell A, Fairchild CJ, Fuldeore MJ, Ollendorf DA, et al. Medication compliance and persistence: terminology and definitions. Value Health. 2008;11(1):44-7.

12. Razali MS, Yahya H. Compliance with treatment in schizophrenia: a drug intervention program in a developing country. Acta Psychiatr Scand. 1995;91(5):331-5.

13. Tebbi CK. Treatment compliance in childhood and adolescence. Cancer. 1993;71(10 Suppl):3441-9.

14. Timmerman L, Stronks DL, Groeneweg JG, Huygen FJ. Prevalence and determinants of medication non-adherence in chronic pain patients: a systematic review. Acta Anaesthesiol Scand. 2016;60(4):416-31.

15. Cardoso MG, Weinstock JG, Sardá Júnior JJ. Adhesion to neuropathic pain treatment. Rev Dor. 2016;17(Suppl 1):S107-9

16. Kurita GP, Pimenta CA. [Compliance with the treatment of chronic pain and health locus]. Rev Esc Enferm USP. 2004;38(3):254-61. Portuguese.

17. Mastroianni PC, Oliveira AR, Nadai TR, Lucchetta RC. Economic indicators for drug acquisition. J Bras Econ Saúde. 2017;9(2):177-84.

18. Heymann RE, Paiva Edos S, Helfenstein M Jr, Pollak DF, Martinez JE, Provenza JR, et al. Brazilian consensus on the treatment of fibromyalgia]. Rev Bras Reumatol. 2010;50(1):56-66. English, Portuguese.

19. Bordson SJ, Atayee RS, Ma JD, Best BM. Tricyclic antidepressants: is your patient taking them? Observations on adherence and unreported use using prescriber-reported medication lists and urine drug testing. Pain Med. 2014;15(3):355-63.

20. Cui Z, Zhao Y, Novick D, Faries D. Predictors of duloxetine adherence and persistence in patients with fibromyalgia. J Pain Res. 2012;5:193-201.

21. Able $S$, Cui Z, Shen W. Medication adherence and persistence in patients treated with duloxetine. Value Health. 2012;15(4):A1-256.

22. Sanchez RJ, Mardekian J, Clair AG, Cappelleri JC. Therapeutic and subtherapeutic dosing of pregabalin: medication adherence, healthcare resource utilization, and costs. Am J Pharm Benefits. 2012;4(4):158-64.

23. Dobkin PL, Sita A, Sewitch MJ. Predictors of adherence to treatment in women with fibromyalgia. Clin J Pain. 2006;22(3):286-94.

24. Hyland ME, Hinton C, Hill C, Whalley B, Jones RC, Davies AF. Explaining unexplai- ned pain to fibromyalgia patients: finding a narrative that is acceptable to patients and provides a rationale for evidence based interventions. Br J Pain. 2016;10(3):156-61.

25. Kenny DT. Constructions of chronic pain in doctor-patient relationships: bridging the communication chasm. Patient Educ Couns. 2004;52(3):297-305.

26. Asbring P, Närvänen AL. Ideal versus reality: physicians perspectives on patients with chronic fatigue syndrome (CFS) and fibromyalgia. Soc Sci Med. 2003;57(4):711-20.

27. Perrot S, Choy E, Petersel D, Ginovker A, Kramer E. Survey of physician experiences and perceptions about the diagnosis and treatment of fibromyalgia. BMC Health Serv Res. 2012;12:356.

28. Clauw DJ. Fibromyalgia: more than just a musculoskeletal disease. Am Fam Physician. 1995;52(3):843-51, 853-4. Erratum in: Am Fam Physician. 1996;54(6):1896.

29. Buckelew SP. Behavioral interventions and fibromyalgia. J Musculoskel Pain. 1994;2:153-61

30. McCain GA. Treatment of fibromyalgia syndrome. J Musculoskel Pain. 1994;2:93-104

31. Pioro-Boisset M, Esdaile JM, Fitzcharles MA. Alternative medicine use in fibromyalgia syndrome. Arthritis Care Res 1996;9(1):13-7.

32. Burckhardt CS, Clark SR, Bennett RM. Fibromyalgia and quality of life: a comparative analysis. J Rheumatol. 1993;20(3):475-9.

33. Ryan S. Fibromyalgia: what help can nurses give? Nurs Stand. 1995;9(37):25-8.

34. Uveges JM, Parker JC, Smarr KL, McGowan JF, Lyon MG, Irvin WS, et al. Psychological symptoms in primary fibromyalgia syndrome: relationship to pain, life stress, and sleep disturbance. Arthritis Rheum. 1990;33(8):1279-83.

35. Wolfe F, Hawley DJ. Measurement of the quality of life in rheumatic disorders using the EuroQoL. Br J Rheumatol. 1997;36(7):786-93.

36. Henriksson CM. Longterm effects of fibromyalgia on everyday life. A study of 56 patients. Scand J Rheumatol. 1994;23(1):36-41.

37. Schaefer KM. Struggling to maintain balance: a study of women living with fibromyalgia. J Adv Nurs. 1995;21(1):95-102.

38. Marques AP, Ferreira EA, Matsutani LA, Pereira CA, Assumpção A. Quantifying pain threshold and quality of life of fibromyalgia patients. Clin Rheumatol. 2005;24(3):266-71.

39. Bolwijn PH, van Santen-Hoeufft MH, Baars HM, Kaplan CD, van der Linden S. The social network characteristics of fibromyalgia patients compared with healthy controls. Arthritis Care Res. 1996;9(1):18-26.

40. Bolwijn PH, van Santen-Hoeufft MH, Baars HM, van der Linden S. Social network characteristics in fibromyalgia or rheumatoid arthritis. Arthritis Care Res. 1994;7(1):46-9.

41. Verbunt JA, Pernot DH, Smeets RJ. Disability and quality of life in patients with fibromyalgia. Health Qual Life Outcomes. 2008;6:8.

42. Boisset-Pioro MH, Esdaile JM, Fitzcharles MA. Sexual and physical abuse in women with fibromyalgia syndrome. Arthritis Rheum. 1995;38(2):235-41

43. Yi TI, Kim BK, Ha SA, Lim JY. The relationships between determination of treatmen success and emotional factors in patients with chronic musculoskeletal pain. Ann Rehabil Med. 2014;38(1):77-83.

44. Strömbeck B, Ekdahl C, Manthorpe R, Wilkström I, Jacobsson L. Health-related quality of life in primary Sjögren's syndrome, rheumatoid arthritis and fibromyalgia compared to normal population data using SF-36. Scand J Rheumatol. 2000;29(1):20-8.

45. Culos-Reed SN, Brawley LR. Fibromyalgia, physical activity, and daily functioning: the importance of efficacy and health-related quality of life. Arthritis Care Res. 2000;13(6):343-51.

46. Moretti FA, Silva SS, Novoa CG. Characteristics and perception of social support by patients with fibromyalgia in Facebook. Br J Pain. 2018;1(1):4-8.

47. van Uden-Kraan CF, Drossaert CH, Taal E, Shaw BR, Seydel ER, van de Laar MA. Empowering processes and outcomes of participation in online support groups for patients with breast cancer, arthritis, or fibromyalgia. Qual Health Res. 2008;18(3):405- 